\title{
Epidemiology in oral antidiabetic poisoning in children and adolescents - a four-year study in a pediatric poison centre
}

\author{
Dana Adriana Dascultu', Elena Madalina Petran ${ }^{1,2}$, Coriolan Emil Ulmeanu ${ }^{1,2}$ \\ 1"Grigore Alexandrescu" Emergency Children Clinical Hospital, Bucharest, Romania \\ 2"Carol Davila" University of Medicine and Pharmacy, Bucharest, Romania
}

\begin{abstract}
Oral antidiabetics have become a common etiology associated with acute poisoning in children. The study shall carry out an analysis of the demographic characteristics, circumstantial characteristics and clinical profile associated with oral antidiabetic poisoning. An observational, descriptive and retrospective study was carried out over a period of 4 years including children confirmed with the diagnosis of acute poisoning with oral antidiabetics. In the study group, there is a prevalence of voluntary acute poisoning in female patients in the 15 to 18 year age group. bln the group study biguanides were the most frequent pharmaceutical dugs involved. The predominant clinical manifestations associated with oral antidiabetic intoxications were gastrointestinal.
\end{abstract}

Keywords: oral antidiabetic, voluntary acute poisoning, adolescent, gastrointestinal symptoms

\section{INTRODUCTION}

Acute poisoning in children as reported by the World Health Organization are one of the main causes of mortality in this population group with more than 3,000 deaths per year (1). A national epidemiological study carried out over the period 2006-2010 analized 6,099 cases of acute intoxication in children and concluded that the predominant etiology involved was medication (2). Oral antidiabetics are a frequent etiology associated with acute poisoning in children as a result of the increased number of cases of type II diabetes and thus the increase in their use. The mechanisms of action of oral antiabetics are as follows: sulfonylureas and meglitinides stimulate the endogenous secretion of insulin, biguanides and glitazons increase tissue activity of insulin and $\alpha$-glucosidase inhibitors decrease the intestinal absorption of carbohydrates (3). Newer classes of oral antidiabetics like dipeptide peptidase 4 inhibitors, amyline analogues, glucagon-like peptide-1 agonists, sodium-glucose cotransporter inhibitors act by slowing gastric emptying, reduction of postprandial glucagon production, reduction of dietary intake and blocking renal absorption of glucose (4). Oral antidiabetic agents have been classified according to their effect in hypoglycemic agents such as sulfonylureas and meglitinides and antihyperglycemic agents such as biguanide, glitazons, $\alpha$-glucosidase inhibitors, dipeptide peptidase 4 inhibitors, amyline analogues, glucagon-like peptide-1 agonists, sodiumglucose cotransporter inhibitors (5).

Hypoglycaemia is the main clinical finding associated with oral antidiabetic poisoning and the accompanying signs includes a variety of vegetative manifestations such as gastrointestinal (nausea, vomiting, abdominal pain), skin (hives, erythema polymorph), respiratory (polypnea, pulmonary hypertension), cardiovascular (tachycardia, arterial hypertension), neurological (confusion, agitation, convulsions, coma), musculature (muscle pain, paralysis) and can even lead to acute renal failure and multiple organ failure (6-9). Oral antidiabetic poisoning treatment involves measures to limit toxic absorption via gastro-intestinal decontamination methods, correction of hypoglycaemia and of electrolytic 
and acido-basic imbalances, and renal replacement therapy $(10,11)$.

\section{OBJECTIVES}

We aimed to perform a demographic and circumstantial analysis of oral antidiabetic poisoning in children in order to identify the risk groups for toxic exposure and the clinical profile associated with oral antidiabetic poisoning.

\section{MATERIALS AND METHODS}

\section{Study design}

A descriptive, observational and retrospective study was performed during a four year period (20142018) in the Toxicology-intensive Care Department of the Emergency clinical Hospital for children "Grigore Alexandrescu“" in Bucharest. All pediatric patients ( $0-18$ years old) with acute antidiabetic poisoning were included in the study.

Inclusion criteria were:

- Age $<18$ years old

- Ingestion of oral antidiabetic intentional or accidental, associated with or whitout other medications

- Occurence of the event during 2014-2018

- No other preexisting medical condition

Exclusion criteria included:

- Age $>18$ years old

- Other diagnsotic than mentioned before

- Other medical conditions

- Occurence of the event in other period than 2014-2018

Patients' specific data - age, gender, intention, number and type of drugs ingested, clinical signs were collected from medical charts.

\section{Statistical analysis}

A database was created and analyzed using IBM SPSS to establish the statistical significance of associations between the various variable (gender, background, etiology, age). For the group study averages, percentages were calculated.

\section{Medical ethics issues}

The analysis of the medical chart was carried out in accordance with the applicable medical legislation.

\section{RESULTS}

39 children were admitted with oral antidiabetic poisonig in the Toxicology Department of "Grigore Alexandrescu" Children Emergency Hospital in Bucharest in a four-year period (2014-2018).

\section{Demographic analysis}

The patients included in the study group are 2-18 years old, with an average age of $11.75 \pm 5.65$ years, with the youngest patient diagnosed with acute oral antidiabetic poisoning being 2 years old. Distribution of patients in the study group by age shows an incidence peak in the age group 15-18 years old (43.5\%) (Fig. 1).

According with gender distribution 32 (82\%) were females and $7(17.95 \%)$ were male, with a female/male ratio of $4.5: 1$.

The distribution of patients in the study group according to their residence identifies that $13(33.3 \%)$ patients come from rural areas and 26 (66.6\%) from urban areas.

Intentional poisoning has been more common compared to accidental poisoning, with 29 cases of intentional poisoning $(74.36 \%)$ and only 10 cases of accidental poisoning (25.64\%).

In $9(23.08 \%)$ cases we identified ingestion of only one toxicant and in $30(63.33 \%)$ cases other pharmaceutical drugs than oral antidiabetic were ingested (table 2).

According with etiology the majority of cases $32(80 \%)$ the toxicant involved was biguanides, in 7 $(17.5 \%)$ cases sulfonylureas poisoning was identified and only one case with meglitinides poisoning (figure 2).

In the study group for the 39 patients it is noted that: 30 patients $(56 \%)$ showed gastrointestinal symptoms, 20 patients (37\%) had neurological symptoms and only 4 (7\%) patients had cardiac symptoms (Figure 3).

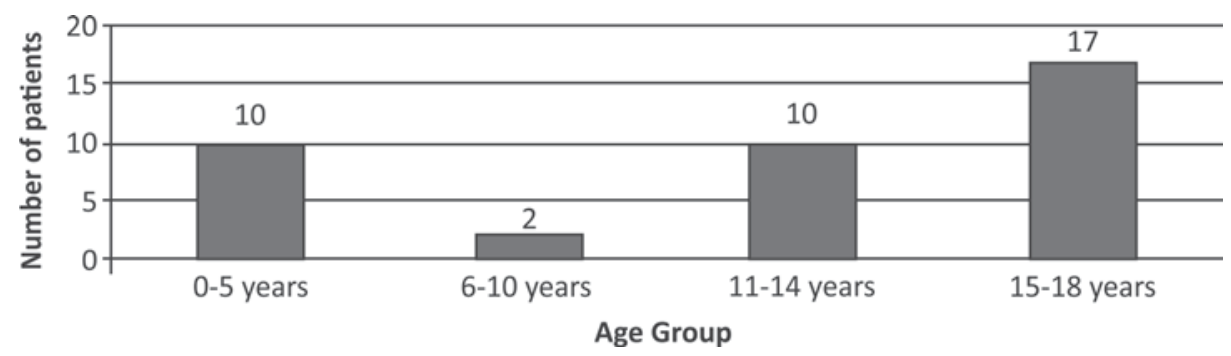

FIGURE 1. Age distribution 
TABLE 1. Age group, gender, residence distribution

\begin{tabular}{|l|c|c|c|c|c|c|}
\hline Residence & Gender & $\begin{array}{c}\text { Group age } \\
\text { 0-5 years }\end{array}$ & $\begin{array}{c}\text { Group age } \\
\text { 6-10 years }\end{array}$ & $\begin{array}{c}\text { Group age } \\
\text { 11-14 years }\end{array}$ & $\begin{array}{c}\text { Group age } \\
\text { 15-18 years }\end{array}$ & Total \\
\hline Rural & $\begin{array}{c}\text { Female } \\
\mathrm{N}(\%) \\
\text { Male } \\
\mathrm{N}(\%)\end{array}$ & $1(2.5 \%)$ & $0(0)$ & $4(7.69 \%)$ & $8(20.5 \%)$ & $13(33.3 \%)$ \\
& Total & $1(2.5 \%)$ & $0(0)$ & $4(10.25 \%)$ & $8(20.5 \%)$ & $13(33.3 \%)$ \\
\hline Urban & $\begin{array}{c}\text { Female } \\
\mathrm{N}(\%) \\
\text { Male } \\
\mathrm{N}(\%)\end{array}$ & $2(5.1 \%)$ & $2(5.1 \%)$ & $6(15.38 \%)$ & $9(23 \%)$ & $19(51.28 \%)$ \\
& Total & $9(23 \%)$ & $2(5.1 \%)$ & $6(15.38 \%)$ & $11(28.2 \%)$ & $26(66.6 \%)$ \\
\hline Total & & 10 & 2 & 10 & 17 & 39 \\
\hline
\end{tabular}

TABLE 2. Gender, poisoning event and circumnstance distribution

\begin{tabular}{|l|c|c|c|c|}
\hline Poisoning event & Multiple drug ingestion & One drug ingestion & Female & Male \\
\hline Intentional & $26(66.6 \%)$ & $3(7.69 \%)$ & $26(66.6 \%)$ & $1(2.6 \%)$ \\
\hline Accidental & $0(0 \%)$ & $10(25.64 \%)$ & $6(15.38 \%)$ & $6(15.38 \%)$ \\
\hline Total & $30(76.9 \%)$ & $9(23.08 \%)$ & $32(28.05 \%)$ & $7(18 \%)$ \\
\hline
\end{tabular}

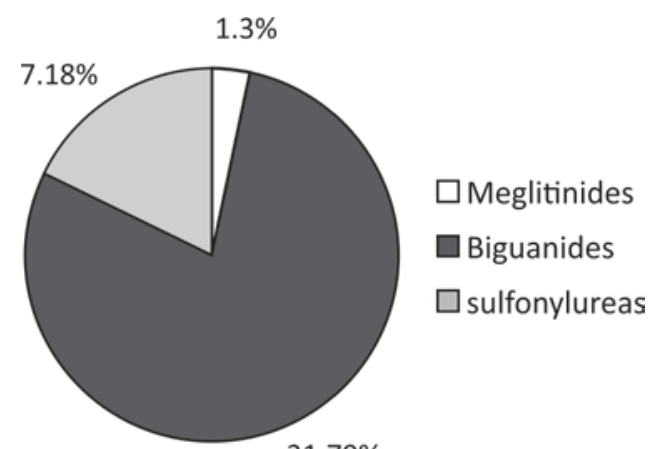

$31.79 \%$

FIGURE 2. Distribution of cases according to the etiolgy of poisoning

The association of clinical manifestations and toxic exposure to biguanid and sulfonylureas was also analyzed and a predominance of gastrointestinal symptoms associated with these poisoning was observed (tables 3 and 4).

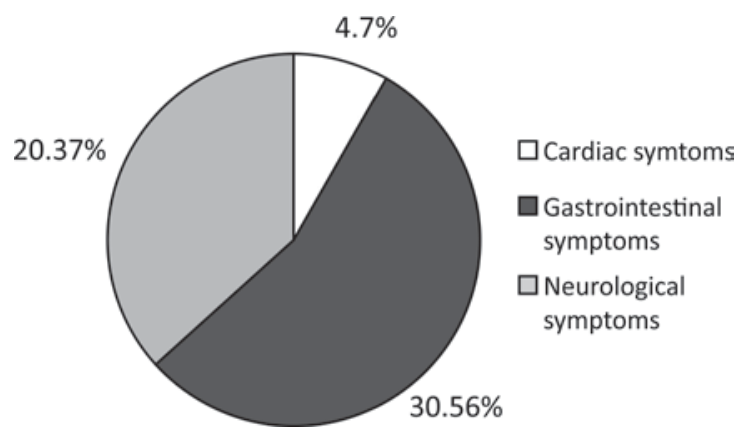

FIGURE 3. Distribution of cases by symptoms

\section{DISCUSSION}

Acute poisoning with oral antidiabetics have increased in frequency in the pediatric population as a result of increased accessibility to these pharmaceuti-

TABLE 3. Presence of symptoms by age group in patients with sulfonylureas poisoning

\begin{tabular}{|l|c|c|c|c|}
\hline $\begin{array}{l}\text { Age group } \\
\text { (years) }\end{array}$ & $\begin{array}{c}\text { Nr. cases cardiac } \\
\text { symptoms (\%) }\end{array}$ & $\begin{array}{c}\text { Nr. cases neurological } \\
\text { symptoms (\%) }\end{array}$ & $\begin{array}{c}\text { Nr.cases gastrointestinal } \\
\text { symptoms (\%) }\end{array}$ & $\begin{array}{c}\text { Total nr. cases } \\
\text { of poisoning }\end{array}$ \\
\hline $0-5$ years & $0(0)$ & $1(50 \%)$ & $2(100 \%)$ & 2 \\
\hline $6-10$ years & $0(0)$ & $0(0 \%)$ & $0(0)$ & 0 \\
\hline $11-14$ years & $1(100 \%)$ & $1(100 \%)$ & $1(100 \%)$ & 1 \\
\hline $15-18$ years & $1(25 \%)$ & $2(50 \%)$ & $3(75 \%)$ & 4 \\
\hline
\end{tabular}

TABLE 4. Presence of symptoms by age group in patients with biguanide poisoning

\begin{tabular}{|l|c|c|c|c|}
\hline $\begin{array}{l}\text { Age group } \\
\text { (years) }\end{array}$ & $\begin{array}{c}\text { Nr. cases cardiac } \\
\text { symptoms (\%) }\end{array}$ & $\begin{array}{c}\text { Nr.cases neurological } \\
\text { symptoms (\%) }\end{array}$ & $\begin{array}{c}\text { Nr.cases gastrointestinal } \\
\text { symptoms (\%) }\end{array}$ & $\begin{array}{c}\text { Total nr. cases } \\
\text { of poisoning }\end{array}$ \\
\hline $0-5$ years & 0 & $3(37.5 \%)$ & $5(62.5 \%)$ & 8 \\
\hline $6-10$ years & $1(50 \%)$ & $2(100 \%)$ & $2(100 \%)$ & 2 \\
\hline $11-14$ years & $2(25 \%)$ & $3(37.5 \%)$ & $7(87.5 \%)$ & 8 \\
\hline $15-18$ years & $1(7.69 \%)$ & $10(76.9 \%)$ & $11(84.61 \%)$ & 13 \\
\hline
\end{tabular}


cal drugs. Analyzing the acute poisoning cases admitted in the Toxicology Department of the Emergency Clinical Hospital for children „Grigore Alexandrescu" in Bucharest, we have seen a $0.8 \%$ increase in the prevalence of acute poisoning by oral antidiabetic poisoning in the period 2014-2018 compared to the 2010-2014. This phenomenon is explained by the large number of adults diagnosed with type 2 diabetes mellitus who benefit from oral antidiabetes treatment and easy access of children to these types of medication. In literature are few studies in regard oral antidiabetic poisoning in children.

When analyzing the distribution of patients with oral antidiabetic poisoning by age group, the age group 15-18-year-olds is best represented $(\mathrm{n}=17$, $43.58 \%$ ) and an equal percentage distribution for the 11-14-year and 0-5-year-olds is obeserved.This findings are in accordance with the literature data. According to literature data there is a predominance of poisoning cases in adolescents particulary through toxic exposure to pharmaceutical drugs. Data collected from United States of America antitoxic centers reveals that acute poisoning are more frequent in adolescents and the mortality associated with toxic exposures is at a maximum in the age group 13-19 years. The 2019 Annual Report of the American Association of Poison Control Centers reported a number of 86 fatalities associated with toxic exposures an $8 \%$ increase compared to 2018 report, of which 71 cases were associated with drug poisoning (12).

$29(25.64 \%)$ cases of intentional oral antidiabetic poisoning was identified in the group study. Correlating the instances of drug exposure, age, gender, residence we observed that the events in children under 5 years old occured accidental and those in children over 15 years old were intetional. An epidemiological study carried out in Romania during the period $1997-2000$ on 11,890 patients admitted in the antitoxic center of the Emergency clinical Hospital for children „Grigore Alexandrescu” in Bucharest revealed a predominance of cases of accidental toxic exposure to the patient age group 1-4 years (65\%) and male (13).

According with the data collected from United States of America antitoxic centers regarding the instances of drug exposure accidental toxic exposure were more frequent in children under 5 years old meanwhile intentional toxic exposure was predominat in children over 13 years old (12).

In $30(76.9 \%)$ cases data showed ingestion of more than one drug. Correlating the number and type of drugs ingested, gender, age and instances of drug exposure we identified a predominance of acute intentional multidrug poisoning in teenagers girls. This finding is supported by a an epidemiological study carried out during the period 2006-2010 on 6099 patients admitted in four pediatric antitoxic centers in Romania who revealed a predominance of cases of intentional toxic exposure (82\%) in females (2).

Analyzing the etiology of poisoning in the group study we identified that in $32(80 \%)$ cases the drug involved was a biguanide, phenomen explained by the extensive use of biguanides-metformin in monotherapy or in association with other oral antidiabetic in treating type II diabetes mellitus. In 2018 metformin was the fourth most prescribed drug with almost 83 million prescriptions, being the most widely used medication for diabetes (14).

The clinical manifestations associated with oral antidiabetic poisoning were predominantly gastrointestinal ( $\mathrm{n}=30,56 \%)$. An analysis of clinical symptoms in correlation with the etiology of toxic exposure has identified in the group study that in both biguanid and sulfonylureic poisoning gastrointestinal symptoms are dominant. Sulfonylurea poisoning leads to hypoglycaemia which can be clinically expressed as: nausea vomiting, abdominal pain. The expert reviews identified an increased incidence of the use of metformin and the appearance of digestive symptoms (15). Metformin poisoning according with the data collected by the United States regional antitoxic centers have shown that for 55 patients with acute metformine poisoning the primary clinical findings were gastrointestinal as follows: nausea (2 patients), diarrhea (2 patients) (16).

\section{CONCLUSIONS}

Acute oral antidiabetic poisoning has the potential to evolve to severe forms with high lethality, especially if they evolve with acute renal failure or refractory lactic acidosis.

Increasing prevalence of the use oral antidiabetic agents implies a high exposure tare of this type of medication as toxicant in children and adolescents. Information campaigns need to be launched with regard to the toxic potential of such medication and regulatory measures to limit access for pediatric patients to oral antidiabetic agents are required. 


\section{REFERENCES}

1. Dinesh S, Towner E, Vincenten J, Segui-Gomez M, Racioppi F. European Report on Child Injury Prevention. Available at: http://www. who.int/violence_injury_prevention/child/injury/world_report/ European_report.pdf.

2. Ulmeanu C, Nițescu V, Bizo A, Gafencu M, lordache C, Jitareanu C. Epidemiologia intoxicațiilor acute la copil în România - studiu multicentric pe 5 ani. Congresul Național de Pediatrie; București, 2011.

3. Meneses MJ, Silva BM, Sousa M, Sá R, Oliveira PF, Alves MG. Antidiabetic Drugs: Mechanisms of Action and Potential Outcomes on Cellular Metabolism. Curr Pharm Des. 2015;21(25):3606-20.

4. Defronzo RA, Ferrannini E, Keen H, Zimmet $P$ (eds.). International Textbook of Diabetes Mellitus, vol. 2. Jon Wiley \& Sons 1992;773-791.

5. Lorenzati B, Zucco C, Miglietta S, Lamberti F, Bruno G. Oral Hypoglycemic Drugs: Pathophysiological Basis of Their Mechanism of Action Oral Hypoglycemic Drugs: Pathophysiological Basis of Their Mechanism of Action. Pharmaceuticals (Basel). 2010; 3(9):3005-3020.

6. Seltzer HS. Drug-induced hypoglycemia: a review of 1418 cases. Endocrinol Metab Clin North Am. 1989;18:163-83.

7. Haymond MW. Hypoglycemia in infants and children. Endocrinol Metab Clin North Am. 1989;18:211-52.

8. Field JB. Hypoglycemia: definition, clinical presentations, classification, and laboratory tests. Endocrinol Metab Clin North Am. 1989;18:27-43.
9. Cryer PE. Hypoglycemia: pathophysiology, diagnosis, and treatment. Oxford: Oxford University Press; 1997.

10. Ghannoum M, Gosselin S. Enhanced poison elimination in critical care. Adv Chronic Kidney Dis. 2013;20(1):94-101.

11. American Academy of Clinical Toxicology, European Association of Poisons Centres and Clinical Toxicologists. Position paper: single-dose activated charcoal. Clin Toxicol. 2005;43(2):61-87.

12. Mowry JB, Spyker DA, Brooks DE, McMillan N, Schauben JL. 2014 Annual Report of the American Association of Poison Control Centers' National Poison Data System (NPDS): 32nd Annual Report. Clin Toxicol (Phila). 2015;53(10):962-1147.

13. Nițescu V. Afectarea hepatică și renală în intoxicațiile acute medicamentoase la copil. Protocoale terapeutice. Teză de doctorat. București: UMF „Carol Davila“, 2007.

14. Holman R. Metformin as first choice in oral diabetes treatment: the UKPDS experience. Journ Annu Diabetol Hotel Dieu. 2007:13-20.

15. McCreight LJ, Bailey CJ, Pearson ER. Metformin and the gastrointestinal tract. Diabetologia. 2016;59(3):426-435.

16. Spiller HA, Weber JA, Winter ML, Klein-Schwartz W, Hofman M, Gorman SE, Stork CM, Krenzelok EP. Multicenter case series of pediatric metformin ingestion. Ann Pharmacother. 2000 Dec;34(12):1385-8. 